\title{
Reply to the letter by S. Niedzwecki regarding our article "Serum levels of interleukin-1 receptor antagonist (IL-1ra) in thyroid cancer patients"
}

\author{
Sebastian Niedźwiecki
}

Received: 24 August 2008 / Accepted: 16 September 2008 / Published online: 18 October 2008

(C) Springer-Verlag 2008

We are content with Dr. Kapoor's comment concerning the results of our study on potential clinical utility of the interleukin-1 receptor antagonist (IL-1 ra) determination in peripheral blood of thyroid cancer patients. We believe that articles cited by Dr. Kapoor include promising data elucidating the role of IL-1/ IL-1ra system in the development, progression and metastases formation of various endocrine-related cancers. In our opinion, the explanation of IL-1ra potential role in cancer development needs twoway researches. On the one hand, the direct impact of IL1ra on cancer cells should be revealed, especially on the molecular level (gene polymorphism and mutation). On the other hand, the significance of the determination of the serum Il-1 ra and other pro-inflammatory cytokines levels in processes accompanying human malignancy (e.g. inflammation, wound healing) remains to be elucidated. Furthermore, the close relationship between IL-1ra, interleukin-1 and interleukin-6 remains to be still up for discussion.

However, in the light of our observation, increased IL1ra concentration in human plasma can be a useful, additional diagnostic and prognostic biomarker for the presence thyroid gland malignancy. The role of Il-1ra serum levels estimation in patients with other endocrine gland tumors pathology is yet to be determined.
S. Niedźwiecki $(\square)$

Department of Endocrine and General Surgery,

Medical University of Łódź, Copernicus Memorial Hospital,

ul. Pabianicka 62,

93-513 Łódź, Poland

e-mail: smpn@op.pl 